FINAL TECHNICAL REPORT

to

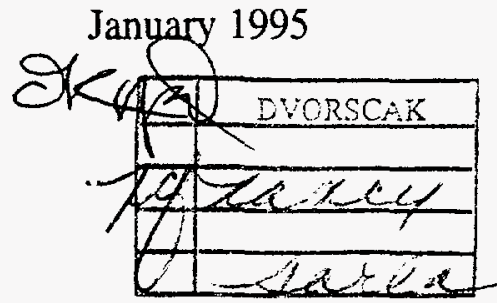

US DEPARTMENT OF ENERGY-PITTSBURGH ENERGY TECHNOLOGY CENTER

Grant No. DE FG 22-90 PC 90099

\title{
RESEARCH ON FUNDAMENTAL ASPECTS OF INORGANIC PARTICLE DEPOSITION IN COAL-FIRED EQUIPMENT
}

Principal Investigator: Prof. Daniel E. Rosner

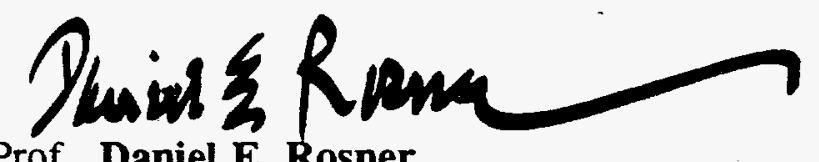

Yale University

High Temperature Chemical Reaction Engineering Laboratory

Department of Chemical Engineering

PO Box 208286 YS, New Haven CT 06520-8286 USA

Period Covered: 6 September 1990 to 31 October 1994

Total Budget: $\$ 317,339$.

Attn: James D. Hickerson (COTR)

A.J. Ferlic

US Dept. Energy-PETC

POB 10940

Pittsburgh PA 15236-0940 USA

M/S 921-118

APPROVED FOR PUBLIC RELEASE: DISTRIBUTION UNLIMITED

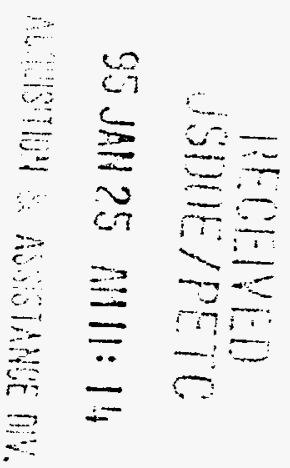

The views and conclusions contained in this document are those of the authors and his research colleagues and should not be interpreted as necessarily the official policy or the endorsements, either expressed or implied, of the Department of Energy or the U.S. Government. 
DOE-PETC Grant No. DE FG 22-90 PC 90099

Final Technical Report

RESEARCH ON FUNDAMENTAL ASPECTS OF INORGANIC PARTICLE DEPOSITION IN COAL-FIRED EOUIPMENT

Principal Investigator: Prof. Daniel E. Rosner

Yale UniversityHigh Temperature Chemical Reaction Engineering Laboratory

Department of Chemical Engineering

PO Box 208286 YS, New Haven CT 06520-8286 USA

ABSTRACT

TABLE OF CONTENTS

1. INTRODUCTION

2. SUMMARY OF RESEARCH ACCOMPLISHMENTS

3. ADMINISTRATIVE INFORMATION: PERSONNEL, PRESENTATIONS, APPLICATIONS

3.1 Personnel

3.2 Coperation with US Industry

3.3 Presentations and Research Training

3.4 Some Known Applications of Yale-HTCRE Lab Research Results

4. CONCLUSIONS, RECOMMENDATIONS

5. REFERENCES

5.1 Cited Background Publications (Predecessor DOE, OSR, NASA-Grants)

5.2 Publications Which Appeared* Based on GRANT DOE-PETC No. DE FG 22-90 PC 90099

5.3 Papers Submitted For Publication, or 'In Press'

LIST OF ABBREVIATIONS

6. APPENDIX 1 "Prediction/Correlation of Particle Deposition Rates From Dilute Polydispersed Flowing Suspensions and the Nature/Properties of Resulting Deposits", Rosner, D.E., et. al.(Vol. II, Proc. 1st Int. Particle Technol. Forum (AIChE), pp 374-381 (1994) 


\section{DISCLAIMER}

This report was prepared as an account of work sponsored by an agency of the United States Government. Neither the United States Government nor any agency thereof, nor any of their employees, make any warranty, express or implied, or assumes any legal liability or responsibility for the accuracy, completeness, or usefulness of any information, apparatus, product, or process disclosed, or represents that its use would not infringe privately owned rights. Reference herein to any specific commercial product, process, or service by trade name, trademark, manufacturer, or otherwise does not necessarily constitute or imply its endorsement, recommendation, or favoring by the United States Government or any agency thereof. The views and opinions of authors expressed herein do not necessarily state or reflect those of the United States Government or any agency thereof. 


\section{DISCLAIMER}

Portions of this document may be illegible in electronic image products. Images are produced from the best available original document. 
DOE-PETC Grant No. DE FG 22-90 PC 90099

Final Technical Report

\begin{abstract}
RESEARCH ON FUNDAMENTAL ASPECTS OF INORGANIC PARTICLE DEPOSITION IN COAL-FIRED EOUIPMENT
\end{abstract}

\author{
Principal Investigator: Prof. Daniel E. Rosner \\ Yale UniversityHigh Temperature Chemical Reaction Engineering Laboratory \\ Department of Chemical Engineering \\ PO Box 208286 YS, New Haven CT 06520-8286 USA
}

\begin{abstract}
We review here results of our recent DOE-PETC research program on the deposition dynamics of combustion-generated particles in power production technologies. In this Final Technical Report, which emphasizes the capture of inertially impacting particles, we outline and illustrate the results of recently developed methods to predict total surface deposition rates and associated convective heat transfer reductions for targets exposed to a distribution of particles suspended in a mainstream. Our methods combine the essential features of recently developed single particle sticking probability laws with correlations of the inertial impaction of particles on targets in high Reynolds number cross-flow, to develop formulae and 'universal' graphs which provide the dependence of particle deposition rates, and associated reductions in convective heat transfer, on such system parameters as mainstream velocity, mean suspended particle size and target size. The deposition rate/deposit microstructue/properties prediction and correlation procedures illustrated here [Appendix 1] can, eg. , be incorporated into improved 'fouling propensity indices', to motivate, evaluate and implement "ruggedization" and/or fouling reduction strategies, and/or incorporated (as subroutines) into more 'comprehensive' CFD models of an entire power plant.

Details of these theoretical studies, and important ancillary matters, will be found in the 22 archival references prepared as part of this program (Section 5.2,5.3). As anticipated, a judicious blend of (numerical and physical) experiments, theory, and intuition was necessary to economically arrive at the methods/results given here. We believe these methods/results will improve the generality and accuracy of particle-deposition-related design calculations for a wide variety of equipment/coal types. Our computational and correlation methods now set the stage for treating more complex situations of practical importance in future power generation applications.
\end{abstract}

$* * * * * * * * *$ 


\section{INTRODUCTION}

The purpose of this report is to summarize our research approach and principal accomplishments under DOE Grant DE FG 22-90 PC 90099 (Technical Monitor: James D. Hickerson) during the nominal 4-year period: 9/6/90-10/31/94 (3-year Program +2 No Cost Extensions). This program was built on the foundation provided by our previous DOE, AFOSR and DOE research (Section 5.1), and contributed in a major way to the production of 22 new archival publications (Sections 5.2, 5.3), of which 12 have already appeared in print (Section 5.2) . Readers interested in greater detail than contained in Section 2 are advised to consult these published papers. Copies can also be obtained by writing to the PI: Prof. Daniel E. Rosner, at the Department of Chemical Engineering, Yale University, New Haven, CT 06520-8286 USA. Comments on, or examples of, the applications of our research (Section 3.4) will be especially welcome.

We review here in broad terms the results of our recent research on the deposition dynamics of combustion-generated particles in coal-fired power production technologies. These include our recently developed methods to predict total surface deposition rates and associated convective heat transfer reductions for cylindrical targets ( eg., boiler tubes) exposed to distribution of particles suspended in the mainstream. By combining the essential features of recently developed single particle sticking probability laws (Konstandopoulos, 1991; Rosner et.al., 1992) with our now widely used (Section 3.4) correlation of the inertial impaction of particles on a circular cylinder in high Reynolds number cross-flow (Israel and Rosner,1983; Konstandopoulos et.al., 1993), we have developed formulae and 'universal' graphs (see, eg., Figs. 3,4 of Appendix 1) which provide the dependence of particle deposition rates, and associated reductions in convective heat transfer, on such system parameters as mainstream velocity, mean particle size and target diameter. The deposition rate prediction procedures illustrated here (see, also, Rosner and Tandon, 1994) are efficient enough to be incorporated into future, improved 'fouling propensity indices' or large scale power plant simulations, and can also be used to motivate, evaluate and implement "ruggedization" and/or fouling reduction strategies. Additionally, as a result of this program we have gained an understanding of the interesting links between deposit microstructure/properties and particle deposition mechanism(s) [Tassopoulos et. al. , 1988, Tassopoulos and Rosner, 1991 ]. For example, we know from these ancillary studies that the local deposit thickness and associated local thermal resistance at any given time on-stream are not determined only by the history of the local particle volume fluxes due to impaction/capture. Moreover, the thermophysical properties of such deposits will generally be anisotropic (see, eg., Tassopoulos and Rosner,1991), and the particle size distribution within such deposits will be systematically shifted from that in the mainstream (Rosner et. al.,1994)

Details of these theoretical studies (Section 5.2), and their immediate laboratory and theoretical antecedents (Section 5.2), will be found in our archival references. Our computational and correlation methods are now being extended to treat more complex situations of practical importance in power generation applications. Indeed, we believe that they provide a rational basis for many future design/optimization studies.

\footnotetext{
*We have adapted and applied the micromechanical theory of incident particle capture (sticking-) fraction, $s$ (which provides the functional form of $s$ when particular projectile particles are directed at particular target materials (including granular deposits; Konstandopoulos,1991) at a known velocity $\mathrm{V}_{\mathrm{p}}$ and angle of incidence $\theta_{\mathrm{i}}$ ( $c f$. the target outward normal). Correlations of our computationally intensive results have then been used to predict local and total particle capture rates for a cylindrical target immersed in a polydispersed suspension of such particulates. We considered (see Appendix 1, Section 4) three distinct classes of single particle capture laws, as follows: constant capture fraction, "on-off" capture behavior (expected on a 'clean' (particle-free) smoothe surface), and capture by a 'granular' deposit (above the particle critical velocity, the sticking probability does not fall abruptly to zero but , rather, exhibits an exponential 'tail' (Appendix 1, Fig.2).
} 


\section{SUMMARY OF PRINCIPAL RESEARCH ACCOMPLISHMENTS}

Most of the results obtained under Grant DE FG 22-90 PC 90099 during '90-'94, contained in the 22 publications cited in Sections 5.2 and 5.3, dealt with developing new/improved methods to Predict Particle Deposition Rates in Engineering Equipment and the Associated Reduction in Convective Heat Transfer Rate (eg., to boiler tubes in the cross-flow of ash-laden streams of PC combustion products). Indeed, the manuscript reproduced in Appendix 1 summarizes the convenient formalism we developed in this program (Rosner and Tandon ,1994) for making rational engineering predictions of particle deposition rates in high-gas velocity particle-laden environments, based, in part, on our recently developed single particle sticking capture laws* (Konstandopoulos (1991); Rosner et al (1992)) for impaction on granular deposits. Exploiting such information, even when available for the particular materials combinations of interest, to anticipate deposition rates in realistic engineering environments is normally a computationally demanding task since it is necessary to track the impingement frequency, velocity and incidence angles of all the different size particles in the mainstream capable of striking the target locations of interest, invoking the abovementioned sticking (or 'rebound') laws at each such point to predict the corresponding cumulative local deposition rate. However, by focusing our attention on the canonical geometry of a circular-cylindrical target in cross-flow and introducing a modest number of defensible approximationstl to summarize the predicted and measured deposition rates on the solid surface of interest, we found a way to carry out the tedious portion of such deposition rate predictions 'once-and-for-all', thereby reducing the engineering problem of predicting target deposition rates, and the associated reduction in convective heat transfer rate, to that of multiplying a readily calculated reference deposition rate $\S$ by a set of 'universal' dimensionless deposition rate functions calculated and reported in the cited papers (see, eg., Figs. 3,4 of Appendix 1). For convenience and generality, our results have been cast in terms of the following dimensionless parameters: ratio of mainstream velocity to the critical velocity for particle rebound from the solid surface, ratio of mean abrasive particle size to the threshold size required for impaction on the circular-cylinder target in the prevailing flow environment, spread of the mainstream particle size distribution (assumed 'log-normal'), and the characteristic 'slip' Reynolds number for the critical size particles in the mainstream. In this way we have shown that many previously observed characteristics of fouling layers, including their frequently "lobular" appearance, can be understood theoretically (cf. Fig. 3, Appendix 1) . As also shown in Rosner and Tandon ,1994, a valuable byproduct of the approach developed in this program is the ability to evaluate the local sensitivity of deposition rates to key system parameters, such as gas velocity, mean particle size in the mainstream and target diameter. Indeed, our results (see, eg., Appendix 1) indicate the presence of interesting opposing tendencies----for example, an increase in gas velocity increases the particle impingement rate but also increases the fraction of impacts leading to rebound. Similarly, an increase in target diameter would reduce the frequency of impacts but increase the likelihood of capture upon each (lower velocity) impact. It is clear that an understanding of these 'tradeoffs' will be necessary to evaluate the efficacy of rival strategies for reducing heat exchanger fouling rates.

\footnotetext{
ITo incorporate the essential physical phenomena in a simple manner without making unrealistic idealizations we adopted the following basic assumptions: A1 Local particle impaction frequencies, velocities, and angle-ofincidence can be obtained from recent correlations summarizing the results of individual suspended non-Brownian particle trajectories calculated for steady, inviscid flow past the target ; A2 Even for impaction on granular deposits, single particle capture probability lawscan be invoked to predict average deposition rates in engineering applications where suspended particles of different sizes arrive over a broad range of impact velocities and incidence angles; A3. 'Rebounding' particles donot appreciably influence incoming particles, nor deposit in appreciable numbers upon reimpaction on the same target; A4 Predicted 'initial' deposition rate trends (spatial distributions) determined on an initially smooth target can be used to anticipate longer time deposition rate trends; A5 The mainstream population of suspended particles is approximately log-normal and the suspended particlevolume fraction, $\phi_{\mathbf{p}}{ }^{i s}$ negligible.
}

\$Our reference deposition rate, written (DR) ref in Appendix 1, is that which would be expected in the prevailing environment if all the mainstream particles had the mean size and were captured upon impacting the target surface. 
Summarizing, in our DOE-sponsored Yale HTCRE Lab research during this program, only briefly reviewed here in view of the availability of the archival publications listed in Sections 5.2,5.3, we have shown that new methods for predicting/correlating particle transport rates, combined with recent advances in particle impact micromechanics and continuum boundary layer theory, provide useful means to incorporate important, but often previously neglected, mass transport phenomena in many PC-fired power generation and hot-gas clean-up engineering design/optimization calculations.

Despite the formidable complexities that must be overcome in the design and operation of power plants utilizing a broad spectrum of pulverized coals, the techniques and results described here are indicative of the useful simplifications and generalizations which have emerged from this program's fundamental DOE-funded research studies of combustion-generated particle transport mechanisms/rates. We hope this Final Report and its supporting papers (Sections 5.2,5.3) will facilitate the refinement and/or incorporation of some of the present ideas into engineering design procedures of much greater generality and reliability. Some of this work has already had a significant impact on engineering practice (Section 3.4).

\section{ADMINISTRATIVE INFORMATION: PERSONNEL, PRESENTATIONS,} APPLICATIONS

The following sections summarize some pertinent 'non-technical' facets of the abovementioned Yale HTCRE Lab/DOE-PETC research program:

\subsection{Personnel}

The present results (Sections 2 and 5) are due to the contributions of the individuals listed in Table 3.1-1, which also indicates the role of each researcher and the relevant time interval of the activity. It will be noted that, in addition to the results themselves, this program has simultaneously contributed to the training of a number of students and 3 recent PhDs, who will now be in an excellent position to make future contributions to technologies oriented toward fossil-energy derived power production.

Table 3.1-1 Summary of Research Participants ${ }^{a}$ on DOE Grant :DE FG 22-90 PC 90099

\section{FUNDAMENTAL ASPECTS OF INORGANIC PARTICLE DEPOSITION IN COAL-FIRED EQUIPMENT}

\begin{tabular}{|c|c|c|c|}
\hline Name & Statusa & Date(s) & Principal Research Activityb \\
\hline Albagli, D. & PDRA & $4 / 92-5 / 94$ & particle prod/char. in CDFs \\
\hline Castillo, J. L. & VS & $8 / 94$ & particle formation in BLs \\
\hline Cohen, R. D. & VS & Spring'93 & aggregate restructuring theory \\
\hline Collins, $\mathrm{J}$. & GRA & '92-'94 & particle formation in BLs \\
\hline Garcia-Ybarra, P. & VS & $8 / 94$ & Xport properties of aggregates \\
\hline Gomez, A. & Asst.Prof. & 92 & Ms. on particle transp. props.(CDFs) \\
\hline Kho, T. & GRA & '92-'94 & erosion of metals \\
\hline Konstandopoulos, A.G. & GRA,PDRA & '92, '93 & combined inertia + thermophoresis \\
\hline Labowsky, M. J. & VS & '91-'94 & inertial impaction and erosion \\
\hline Rosner, D.E. & PI & '91-'94 & program direction-dep. theory \\
\hline Tandon, $\mathrm{P}$. & GRA & '92-'94 & transport phenom. in BLs and CDFs \\
\hline Tassopoulos, $\mathrm{M}$. & GRA & '90-'91 & microstructure of granular deposits \\
\hline Xing, $\mathrm{Y}$. & GRA & '93-'94 & particle prod/char. in CDFs \\
\hline $\begin{array}{l}\text { PDRA=Post- }- \\
\text { PI = Princip }\end{array}$ & , & $\begin{array}{l}\text { Iuate } \\
\text { ing } S\end{array}$ & $c h A$ \\
\hline
\end{tabular}




\subsection{Cooperation with US Industry}

The research summarized here was supported by DOE-PETC under Grant DE FG 22-90 PC 90099 (9/6/90-10/31//94). The Yale HTCRE Laboratory has also been the beneficiary of continuing smaller grants from U.S. industrial corporations, including groups within GE, DuPont, Union Carbide (now Advanced Ceramics Corp.) and Shell, as well as the feedback and advice of principal scientists/engineers from each of these corporations and Combustion Engineering-ABB and Textron. We appreciate this level of collaboration, and expect that it will accelerate inevitable applications of our results in areas relevant to their technological objectives (see, also, Section 3.4, below).

\subsection{Presentations and Research Training}

Apart from the publications itemized in Section 5 and our verbal presentation (of progress) at the regular DOE-PUEC Contractors Meetings, our results have also been presented at some 32 seminars/conferences--including annual or topical conferences of the following professional organizations:

Int. Fine Particle Res. Inst. (6/92, 6/93)

AIChE Annual Meetings (11/90, 11/91, 11/92, 11/93, 11/94)

AAAR (10/93, 9/94)

ASME-Engineering Foundation (3/91)

Combustion Inst.

In addition, during the period: 9/6/90-10/31/94, the PI presented research seminars at the following Universities:

Aristotle U.-Thessaloniki

U Manchester 5/28/92

Northwestern $4 / 22 / 93$

Notre Dame (10/27/92)

Istanbul Tech. U.

U. Oslo

U. Toulouse

ETH-Zurich
Leeds 5/29/92
CUNY 10/18/93
U. Wisconsin
Northwestern U.
U Trondheim
Nat. Tech U-Athens

ETH-Zurich

Leeds 5/29/92

CUNY 10/18/93

. Wisconsin

U Trondheim

Nat. Tech U-Athens
Brown (9/22/92)

Penn State (7/28/92)

KTH-Stockholm

U. Limoges

Technion-Haifa

Waterloo

as well as an invited talk at the IFV power plant in Kalundborg, Denmark. All European lectures listed above were in connection with Prof. Rosner's Yale academic leaves ( Fall '91, Fall '94).

This DOE-PETC program also contributed to the completion of the PhD dissertation research of three Yale graduate students (A.G. Konstandopoulos , M. Tassopoulos and P. Tandon; cf. Table 3.1-1). T. Kho received her Master's Degree based, in part, on erosionoriented work supported in this program (see Section 5.3).

It should be mentioned that A.G. Konstandopoulos and M. Tassopoulos won the student award at the 11/90 AIChE Mtg. for their poster on the microstructure/properties of granular deposits. Moreover, our contribution: "Effect of Radiative Heat Transfer on the Coagulation Dynamics of Combustion-Generated Particles", won the "Best Paper Award" at the 1991 Central States Combustion Institute Mtg.

\subsection{Some Known Applications of Yale-HTCRE Lab Research Results}

It has been particularly gratifying to see direct applications of some of this generic DOEsupported particle mass transfer research in more applications-oriented investigations reported in recent years. Due to the inevitable required lead time, the examples cited here are mainly from the early part of this program. Indeed, the writer would appreciate it if further, more recent examples known to the reader can be brought to his attention. 
In the area of multicomponent vapor deposition in combustion systems applications of our predictive methods (for "chemically frozen" (Rosner et.al., 1979) and LTCE multicomponent laminar boundary layers) have been made by British Coal Corporation-Power Generation Branch (I. Fantom, et.al.) in connection with their topping cycles which run gas turbines on the products of fluidized bed coal combustors/gasifiers. A useful review of our vapor and particle deposition research as of $c a$. 1989, (in the context of fouling research worldwide) may be found in the comprehensive article by Marner, 1989 (Section 5.1). Also, in soot-related combustion research many groups (eg., Dobbins et.al. (Brown U.), Faeth et.al. (U. Mich.), Katz et al. (J. Hopkins U.)) are now utilizing "thermophoretic sampling" techniques to exploit the size- and morphologyinsensitive capture efficiency characteristics that we have proven in our DOE and AFOSR research (Rosner et.al.,1991).

Our DOE- supported research on thermophoretically dominated soot deposition rates from flowing laminar or turbulent combustion gases has been applied by Aerojet Corp. (D. Makel et.al.,1990) to develop a model for application to rocket chambers and nozzles (with NASA support). Extensions to jet engine nozzles are currently being made by M.T. Nys at Pratt and Whitney Engine Business in W. Palm Beach FL.

Ongoing work at MIT (Walsh et.al. 1992), PSI (J.J.Helble) and Sandia CRF (L.L. Baxter) has incorporated our rational correlation of inertial particle impaction (e.g. a cylinder in cross-flow, or a column of such cylinders (Konstandopoulos et. al.,1993)) in terms of our effective Stokes number (Israel and Rosner, 1983, and Konstandopoulos et. al. 1993). Recent applications of our DOE and AFOSR-supported research (on the correlation of inertial impaction by cylinders in crossflow) have also been made by the National Engineering Laboratory (NEL) of Glasgow, Scotland. NEL, as part of an EEC-coordinated program, is apparently developing mass-transfer prediction methods applicable to waste-heat recovery systems in incinerators, as well as pulverized coal-fired boilers. These applications are somewhat similar to those reported by the Combustion R\&D group at MIT and Penn State U, and are now also being taken up by VTTEnergy/Aerosol Technology Group, in Finland.

Explicit use of our studies of self-regulated "capture" of incident impacting particles (Rosner and Nagaragan, 1987) is being made in current work on impact separators and ceramic heat exchangers for coal-fired turbine systems in high performance stationary power plants. Other potential applications arise in connection with "candle filters" used to remove fines (sorbent particles,...) upstream of the turbines. A useful summary of work in these interrelated areas (Solar Turbines, Textron Defense Systems, Hague International,...) was presented at the Engineering Foundation Conference Inorganic Transformations and Ash Deposition During Combustion., the proceedings of which appeared in 1992.

For calculating suspended particle concentrations along trajectories (eg., outside of aircraft involved in atmospheric sampling, or inside of non-isothermal CVD reactors, A. S. Geller et.al. of Sandia-Albuquerque have adopted a method developed in our earlier work (Fernandez de la Mora, 1981), and recently applied in our own studies of particle motion in laminar boundary layers with streamwise curvature (Konstandopoulos and Rosner, 1995---see Section 5.3).

Clearly, fruitful opportunities for applications of our recent particle mass transfer research, including our recent erosion rate prediction/correlation methods (Section 5.3), now exist in many programs currently supported by the US DOE (eg., 'Combustion 2000'), as well as independent civilian sector R\&D. 


\section{CONCLUSIONS, CONCLUSIONS}

In this DOE-sponsored Yale HTCRE Lab researchprogram during the period: 9/6/90$10 / 31 / 94 / 94$, briefly described above, we have shown that our recent advances in particle dynamics and mass transport theory provide useful means to incorporate important, often previously neglected, deposition rate phenomena in power-generation and hot-gas cleanup design/optimization calculations. As anticipated, we made use of a judicious blend of (numerical and physical) experiments, theory, and intuition to economically arrive at computaation/correlation methods/results which will inevitably improve the generality and accuracy of future particle-deposition-related design calculations for a wide variety of equipment/fuel types. In all, some 32 verbal presentations, 12 archival publications (Section 5.2), and $3 \mathrm{PhDs}$ have resulted (in total or in part) from this DOE-PETC research program. Additionally, 10 papers are submitted or in press (see Section 5.3) and should appear in the archival engineering literature before the end of 1995. It should also be noted here that the total funding for this program was $\$ 317,339$.

Despite formidable complexities to be overcome in the design and operation of power plants utilizing a broad spectrum of coal-derived fuels, the techniques and results of this past DOE-PETC program (see Sections 2,5, Appendix 1, and the references cited therein) are indicative of the useful simplifications and generalizations needed to accelerate progress in more efficient coal utilization. It is hoped that this Final Report and its supporting papers (Section 5) will now facilitate incorporatiing these ideas into design and test procedures of far greater generality and reliability. This work has also identified new directions where cost-effective DOEPETC-sponsored research would have a significant impact on engineering practice for coal-fired systems---including those for materials processing as well as power generation. Long-range investigations should continue in each of the fundamental areas summarized above, as well as others beyond the scope of this Final Technical Report. Only then will it be possible to provide engineering designers with significantly better "tools" for making rational assessments of ash deposition phenomena in future, high-performance, reliable coal-fired equipment.

\section{REFERENCES}

\subsection{CITED BACKGROUND PUbLICATIONS (Predecessor DOE, OSR-Grants)}

Castillo, J.L. and Rosner, D.E., "Theory of Surface Deposition from a Binary Dilute VaporContaining Stream, Allowing for Equilibrium Condensation within the Laminar Boundary Layer", Int. J. Multiphase Flow, 15, [1], 97-118 (1989)

Castillo, J.L., and Rosner, D.E. "Non-equilibrium Theory of Surface Deposition from ParticleLaden, Dilute Condensible Vapor -Containing Streams, Allowing for Particle Thermophoresis and Vapor Scavenging within the Laminar Boundary Layer", Int. $J$. Multiphase Flow, 14 (1), pp. 99-120(1988)

Castillo, J.L., Mackowski, D.W., and Rosner, D.E., "Photophoretic Contribution to the Transport of Absorbing Particles Across Combustion Gas Boundary Layers", ACS Symposium Issue: Ash Deposition, Prog. Energy and Comb. Sci. 16, 253-260 (1989)

Eisner, A.D. and Rosner, D.E., Experimental Studies of Soot Particle Thermophoresis in NonIsothermal Combustion Gases Using Thermocouple Response Techniques", Combustion and Flame 61, 153-166(1985); see, also: J PhysicoChemical Hydrodynamics (Pergamon) 7 , 91-100 (1986)

Fernandez de la Mora, J., and Rosner, D.E.,"Inertial Deposition of Particles Revisited and Extended: Eulerian Approach to a Traditionally Lagrangian Problem", J. Physicochemical Hydrodynamics (PCH) (Pergamon) 2, 1-21 (1981); see, also J. Fluid Mech 125, 379-395 (1982) 


\subsection{CITED BACKGROUND PUBLICATIONS (cont.)}

Fernandez de la Mora, J. and Rosner, D.E., "Inertial Deposition of Particles Revisited and Extended: Eulerian Approach to a Traditionally Lagrangian Problem", PCH Physicochemical Hydrodynamics (Pergamon) 2 (1), 1-21, (1981)

Geller, A.S., Rader, D.J. and Kempka, S.N., "Calculation of Particle Concentration Around Aircraft-Like Geometries", J. Aerosol Sci. 24 (6) 823-834 (1993)

Israel, R. and D. E. Rosner, "Use of Generalized Stokes Number to Determine the Aerodynamic Capture Efficiency of Non-Stokesian Particles from a Compressible Gas Flow", Aerosol Sci. Tech., 2, 45-51 (1983)

Konstandopoulos, A.G., Effects of Particle Inertia on Aerosol Transport and Deposit Growth Dynamics, PhD Dissertation, Yale University (December 1991).

Marner, W.J.,"Progress in Gas-Side Fouling of Heat Exchanger Surfaces", in Proc. A.L. London Symposium on Compact Heat Exchangers, pp 421-489, Hemisphere, Washington DC.(1989); also available as: ASME Book \# AMR069 or Appl. Mech Rev 43 (3), 35-66 March (1990)

Park, H. M. and Rosner D. E., "Combined Inertial and Thermophoretic Effects on Particle Deposition Rates in Highly Loaded Dusty-Gas Systems", Chem. Eng. Sci., 44 (10), 22332244 (1989)

Rosner, D.E. and Atkins, R.M., "Experimental Studies of Salt/Ash Deposition Rates from Combustion Products Using Optical Techniques", in Fouling and Slagging Resulting From Impurities in Combustion Gases (Bryers, R. W., ed.), Engineering Foundation, NYC, Publication No. 81-18 (1983), pp.469-492; in particular: Rosner, D.E., Appendix: "Recent Advances in the Theory of Deposition From Combustion Gases", pp. $486-492$

Rosner, D.E., "Total Mass Deposition Rates from 'Polydispersed' Aerosols"; AIChE J. 35, [1], 164-167 (1989)

Rosner, D.E. and Kim, S.S., "Optical Experiments on Thermophoretically Augmented Submicron Particle Deposition From 'Dusty' High Temperature Gas Flows", The Chemical Engrg. J.(Elsevier) 29,[3], 147-157 (1984)

Rosner, D.E. and Nagarajan R.,"Toward a Mechanistic Theory of Net Deposit Growth from Ash-Laden Flowing Combustion Gases: Self-Regulated Sticking of Impacting Particles and Deposit Erosion in the Presence of Vapor 'Glue'", Proc. 24th National Heat Transfer Conf., AIChE Symposium Series, Vol. 83 [257], 289-296, (1987)

Rosner, D.E., Chen, B.K., Fryburg, G.C. and Kohl, F.J., "Chemically Frozen Multicomponent Boundary Layer Theory of Salt and/or Ash Deposition Rates from Combustion Gases", Combustion Science and Technology 20, 87-106 (1979)

Rosner, D.E.and Tassopoulos, M.,"Deposition Rates from 'Polydispersed' Particle Populations of Arbitrary Spread", AIChE J. 35 (9) 1497-1508 (1989)

Rosner, D.E., Transport Processes in Chemically Reacting Flow Systems, Butterworth-Heinemann, Stoneham MA, 1986; 3d Printing 1990. 


\subsection{CITED BACKGROUND PUBLICATIONS (cont.)}

Rosner, D.E., Mackowski, D.W and Garcia-Ybarra, P., "Size and Structure-Insensitivity of the Thermophoretic Transport of Aggregated 'Soot' Particles in Gases", Comb. Sci \& Technology $80(1-3), 87-101(1991)$.

Rosner, D.E., "Experimental and Theoretical Research on the Deposition Dynamics of Inorganic Compounds from Combustion Gases"; Invited paper B. G. Levich Memorial Issue of J. PhysicoChemical Hydrodynamics(PCH) (Pergamon) 10, [5/6], 663-674 (1988)

Rosner, D.E., and Nagarajan, R., "Toward a Mechanistic Theory of Deposit Growth from AshLaden Flowing Combustion Gases: Self-Regulated Sticking of Impacting Particles and Deposit Erosion in the Presence of Vapor 'Glue'", in AIChE Symposium Series, 83, No. 257, Heat Transfer-Pittsburgh 1987 (R.W. Lyczkowski, ed.) 289-296 (1987)

Rosner, D. E. and Fernandez de la Mora J. , "Correlation and Prediction of Thermophoretic and Inertial Effects of Particulate Deposition from Non-Isothermal Turbulent Boundary Layers", in Particulate Laden Flows in Turbomachinery, ASME, NY, $85-94$ (1982)

Rosner, D. E. and Fernandez de la Mora J. , "Boundary Layer Effects on Particle Impaction and Capture", ASME Trans.--J. Fluid Engrg., 106, 113-114 (1984)

Rosner, D. E., Gokoglu, S. and Israel, R., "Rational Engineering Correlations of Diffusional and Inertial Particle Deposition Behavior in Non-Isothermal Forced Convection Environments", in Fouling and Heat Exchanger Surfaces, Engrg. Foundation, NY, 235-256 (1983)

Tassopoulos, M., O' Brien, J. A. and Rosner D .E., "Simulation of Microstructure-Mechanism Relationships in Particle Deposition", AIChE J. 35 (6) 967-980 (1988)

Walsh, P.M., Sarofim, A. F., and Beer, J.M., "Fouling of Convection Heat Exchangers by Lignitic Coal Ash", Energy and Fuels (ACS) 6 (6) 709-715 (1992)

\subsection{PUBLICATIONS WHICH APPEARED* BASED ON GRANT DOE DE FG 22-90 PC 90099}

Castillo, J.L., Garcia-Ybarra, P., and Rosner, D.E.,"Morphological Instability of a Thermophoretically Growing Deposit", J. Crystal Growth 116, 105-126, (1992)

Gomez, A., and Rosner, D.E., "Thermophoretic Effects on Particles in Counterflow Laminar Diffusion Flames " Combustion Science and Technology 89, 335-362 (1993)

Konstandopoulos, A.G., Labowsky, M J., and Rosner, D.E., "Inertial Deposition of Particles From Potential Flows Past Cylinder Arrays", J. Aerosol Sci (Pergamon) 24 (4) 471-483 (1993)

Mackowski, D.W., Tassopoulos, M. and Rosner, D.E.,"Effect of Radiative Heat Transfer on the Coagulation Dynamics of Combustion-Generated Particles", Aerosol Sci. Technol.(AAAR) 20 (1) $83-99,(1993)$

*Not counting our short papers appearing in each of the annual DOE- PUEC Conferences (Nos. 7-10) 


\subsection{PUBLICATIONS WHICH APPEARED (cont.)}

Rosner, D.E., Konstandopoulos, A.G., Tassopoulos, M., and Mackowski, D.W, "Deposition Dynamics of Combustion-Generated Particles: Summary of Recent Studies of Particle Transport Mechanisms, Capture Rates, and Resulting Deposit Microstructure/Properties", Proc. Engineering Foundation Conference: Inorganic Transformations and Ash Deposition During Combustion, Engrg. Foundation/ASME, NYC (1992); pp. 585-606

Rosner, D.E., Tandon, P., Konstandopoulos, A.G., and Tassopoulos, M., ""Prediction/Correlation of Particle Deposition Rates From Dilute Polydispersed Flowing Suspensions and the Nature/Properties of Resulting Deposits" (Vol. II, Proc. 1st Int. Particle Technol. Forum (AIChE), pp 374-381 (1994)

Rosner, D.E., Mackowski, D.W., and Garcia-Ybarra, P., "Size- and Structure-Insensitivity of the Thermophoretic Transport of Aggregated 'Soot' Particles in Gases", Combustion Science and Technology 80,(1-3),87-101(1991)

Rosner, D.E.and Tassopoulos, M.,"Direct Solutions to the Canonical 'Inverse' Problem of Aerosol Sampling Theory: Coagulation and Size-dependent Wall Loss Corrections for LogNormally Distributed Aerosols in Upstream Sampling Tubes", J. Aerosol Sci. 22 (7) 843-867 (1991).

Rosner, D.E., Mackowski, D.W., Tassopoulos, M., Castillo, J.L., and Garcia-Ybarra, P., "Effects of Heat Transfer on the Dynamics and Transport of Small Particles in Gases", I/EC -Research (ACS) 31,760-769 (1992)

Rosner, D.E. and Tandon, P., "Diffusion and Heterogeneous Reaction in Large Multi-particle Aggregates; Calculation and Correlation of 'Accessible' Surface Area", AIChE J. 40 (7) 1167 1182 (1994)

Tassopoulos, M. and Rosner, D.E., "Microstructural Descriptors Characterizing Granular Deposits", AIChE J. 38(1) 15-25 (1991)

Tassopoulos, M., Relationships Between Particle Deposition Mechanism and Resulting Deposit Microstructure/Effective Transport Properties, $\mathrm{PhD}$ Dissertation, Yale University, Dept. Chemical Engineering (1991)

Tassopoulos, M. and Rosner, D.E., "Simulation of Vapor Diffusion in Anisotropic Particulate Deposits", Chem. Eng. Sci. 47(2) 421-443 (1991)

\subsection{PAPERS SUBMITTED FOR PUBLICATION OR IN PRESS}

Konstandopoulos, A.G. and Rosner, D.E.,"Inertial Effects on Thermophoretic Transport of Small Particles to Walls With Streamwise Curvature"---I. Theory, II Experiment, Accepted 1993 and in press, Int. J. Heat Mass Transfer (Pergamon)

Kho, T., Rosner, D.E., and Tandon, P., "Simplified Erosion Rate Prediction Technique for Cylindrical Targets in the High Speed Crossflow of Abrasive Suspensions", (submitted to ASME Trans-J. Engrg. Gas Turbines and Power, 1994)

Rosner, D.E., Tandon, P. and Konstandopoulos, A.G., "Rational Prediction of Inertially Induced Particle Deposition Rates for a Cylindrical Target in Dust-Laden Streams:Effects of Single-Particle Capture Law and Dust Polydispersity on Deposition Rates and Associated Convective Heat Transfer Reductions", (HTCRE Paper No. 202; submitted to Chem. Eng. Sci., summer 1994) 


\subsection{PAPERS SUBMITTED FOR PUBLICATION OR IN PRESS (cont.)}

Rosner, D. E. and Tandon, P. , "Translational Brownian Diffusion Coefficient of Large (Multiparticle) Suspended Aggregates", HTCRE Lab \# 206; Submitted to I/EC-Research

Rosner, D. E., Tandon, P. , and Konstandopoulos, A.G., "Local Size Distributions of Particles Deposited by Inertial Impaction on a Cylindrical Target in Dust-Laden Streams", (in press, J. Aerosol Sci., 1994)

Rosner, D. E., Tandon, P. , and Labowsky, M.J. , "Rapid Estimation of Cylinder Erosion Rates in Abrasive Dust-Laden Streams: Effects of Erosion Rate Law and Dust Polydispersity on Predicted Local and Total Target Wear", (in press, AIChE J., 1995)

Rosner, D. E. and Tandon, P. , "Effective Surface Area/Volume and Sorptive Capacity of Suspended Populations of 'Micro-porous' Particles (Aggregates) Distributed with Respect to both Size (Volume) and Shape", HTCRE \#197, AIChE J (submitted, 1994)

Tassopoulos, M. and Rosner, D.E.,"The Effective Thermal Conductivity of Anisotropic Packings of Spheres" (Part 1."Conduction Through the Solid Phase"; Part 2."Conduction Through the Solid and Void Phases"), Chem. Eng. Sci. (in press(1995))

$$
* * * * * * * * * *
$$

\section{LIST OF ABBREVIATIONS}

$\begin{array}{llll}\text { BL } & \text { Boundary layer } & \text { CDF } & \text { Counterflow diffusion flame } \\ \text { CVD } & \text { Chemical vapor deposition } & \text { CRF } & \text { Combustion Research Facility } \\ \text { Dam } & \text { Damkohler number } & \text { GRA } & \text { Graduate research Asst. } \\ \text { IJHMT Int. J. Heat/Mass Xfer } & \text { CFD } & \text { Computational Fluid Dynamics } \\ \text { PC } & \text { Pulverized Coal } & \text { PSD } & \text { Particle size distribution } \\ \text { LDV } & \text { Laser Doppler Velocimetry } & \text { LTCE local thermochemical equilibrium } \\ \text { TEM } & \text { Transm. Electron } \mu \text {-scope } & \text { pdf } & \text { Probability density function } \\ \text { PI } & \text { Principal Investigator } & \text { VS } & \text { Visiting Scholar } \\ & & & \end{array}$

\footnotetext{
APPENDIX 1 Paper: "Prediction/Correlation of Particle Deposition Rates From Dilute Polydispersed Flowing Suspensions and the Nature/Properties of Resulting Deposits" (Vol. I, Proc. Ist Int. Particle Technol. Forum (AIChE) pp 374-381 (1994)
}

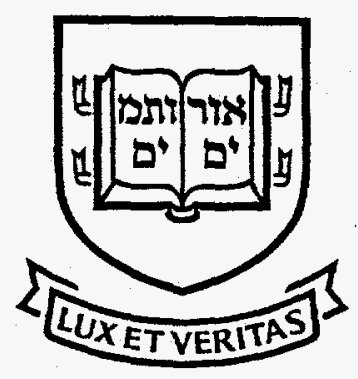

